\title{
The Anxiogenic Drug Yohimbine Reinstates Palatable Food Seeking in a Rat Relapse Model: a Role of CRF, Receptors
}

\author{
Udi E Ghitza', Sarah M Gray', David H Epstein ${ }^{2}$, Kenner C Rice ${ }^{3}$ and Yavin Shaham*,' \\ 'Behavioral Neuroscience Branch, NIDA/IRP/NIHIDHHS, Baltimore, MD, USA; ${ }^{2}$ Clinical Pharmacology and Therapeutics Research Branch, \\ NIDA/IRP/NIHIDHHS, Baltimore, MD, USA; ${ }^{3}$ Laboratory of Medicinal Chemistry, NIDDKINIHIDHHS, Bethesda, MD, USA
}

\begin{abstract}
The major problem in treating excessive eating is high rates of relapse to maladaptive eating habits during diet treatments; this relapse is often induced by stress or anxiety states. Preclinical studies have not explored this clinical problem. Here, we adapted a reinstatement model (commonly used to study relapse to abused drugs) to examine the role of stress and anxiety in relapse to palatable food seeking during dieting. Rats were placed on restricted diet (75-80\% of daily standard food) and for 12 intermittent training days ( $9 \mathrm{~h} /$ day, every other day) lever-pressed for palatable food pellets (25\% fat, $48 \%$ carbohydrate) under a fixed ratio I (20-s timeout) reinforcement schedule. Subsequently, the rats were given 10 daily extinction sessions during which lever presses were not reinforced, and were then injected with yohimbine (an $\alpha$-2 adrenoceptor antagonist that induces stress and anxiety in humans and non-humans) or given a single food pellet to assess reinstatement of food seeking. The rats rapidly learned to lever press for the palatable pellets and across the training days the ratio of timeout nonreinforced lever presses to reinforced lever presses progressively increased more than three-fold, suggesting the development of compulsive eating behavior. After extinction, yohimbine injections and pellet priming reliably reinstated food seeking. The corticotropin-releasing factor, $\left(\mathrm{CRF}_{1}\right)$ receptor antagonist antalarmin attenuated the reinstatement induced by yohimbine, but not pellet priming. Antalarmin also reversed yohimbine's anxiogenic effects in the social interaction test. These data suggest that CRF is involved in stress-induced relapse to palatable food seeking, and that CRF, antagonists should be considered for the treatment of maladaptive eating habits.
\end{abstract}

Neuropsychopharmacology (2006) 31, 2188-2196. doi: I 0.1038/sj.npp. I 300964; published online 7 December 2005

Keywords: corticotropin-releasing factor; extinction; noradrenaline; palatable food; relapse; reinstatement; stress

\section{INTRODUCTION}

The major problem in dietary treatment of excessive eating is high rates of relapse to the maladaptive eating habits (Peterson and Mitchell, 1999). This relapse is often induced by stress and anxiety states (Herman and Polivy, 1975; Crowther et al, 2001). Surprisingly, this issue has not yet been explored in preclinical studies, which have focused instead on the effect of stress on ongoing feeding behavior (Morley et al, 1983; Dallman et al, 2003; Hagan et al, 2003). The neuronal mechanisms underlying drug reward are known to overlap with those of food reward (Colantuoni et al, 2002; Volkow and Wise, 2005). Therefore, a preclinical reinstatement model that has been used to study relapse to abused drugs

*Correspondence: Dr Y Shaham, Behavioral Neuroscience Branch, IRP/NIDA/NIH, 5500 Nathan Shock Drive, Baltimore, MD 21224 , USA, Tel: + I 4I0 550 1746, Fax: + | 410550 1612,

E-mail: yshaham@intra.nida.nih.gov

Received 7 July 2005; revised 14 September 2005; accepted 12 October 2005

Online publication: 13 October 2005 at http://www.acnp.org/citations/ Npp $101305050439 /$ default.pdf
(Stewart, 2000; See, 2002; Shalev et al, 2002) can also be employed to explore mechanisms underlying relapse to maladaptive food-taking behavior. In the reinstatement model, laboratory animals are trained to self-administer drugs and are then given extinction training during which lever presses are not reinforced. Reinstatement of lever responding (the operational measure of drug seeking) is then determined after exposure to drug or non-drug stimuli (de Wit and Stewart, 1981; Stewart and de Wit, 1987; Shaham et al, 2003).

Recent studies using the reinstatement model showed that the $\alpha-2$ adrenoceptor antagonist yohimbine reinstates cocaine seeking in monkeys (Lee et al, 2004) as well as alcohol and methamphetamine seeking in rats (Shepard et al, 2004; Le et al, 2005). Yohimbine is a commonly used pharmacological stressor that increases brain noradrenaline cell firing (Aghajanian and VanderMaelen, 1982) and release (Abercrombie et al, 1988), and induces stress- and anxiety-like symptoms in both humans and non-humans (Holmberg and Gershon, 1961; Lang and Gershon, 1963; Davis et al, 1979; Charney et al, 1983; Bremner et al, 1996a,b). An important finding from the studies with the methamphetamine- and alcohol-trained 
rats (Shepard et al, 2004; Le et al, 2005) was that the effect of yohimbine on reinstatement of drug seeking was generally stronger and more robust than that of intermittent footshock. Footshock is a common laboratory stressor (Van Loon et al, 1989) that over the last decade has been used by several investigators to explore the neuronal mechanisms of stress-induced relapse to drug seeking (Shaham et al, 2000a; Le and Shaham, 2002; Lu et al, 2003; Bossert et al, 2005).

Based on the findings of Le et al (2005) and Shepard et al (2004), we used yohimbine as a stressor and adapted the reinstatement model to study stress-induced relapse to palatable food seeking. Rats were placed on a restricted diet $(75-80 \%$ of their regular standard food) and were trained to lever press for palatable food pellets $(25 \%$ fat, $48 \%$ carbohydrate) for $9 \mathrm{~h} /$ day every other day. We chose this training schedule and diet conditions because previous nonoperant food-consumption studies have shown that rats placed on a restricted diet and given intermittent access to palatable food develop binge-like eating behavior (Colantuoni et al, 2002; Corwin and BudaLevin, 2004) and become hypersensitive to the effect of stress on palatable food intake (Hagan et al, 2002, 2003). After self-administration training, the rats were subjected to extinction training during which lever presses were not reinforced. Reinstatement of extinguished lever responding was then determined after injections of yohimbine or noncontingent exposure to a food pellet, a condition known to reinstate extinguished food responding (de Wit, 1996). We tested our rats under a restricted-diet condition because clinical studies indicate that humans are particularly vulnerable to the effect of stress on feeding behavior when dieting (Herman and Polivy, 1975; Elfhag and Rossner, 2005).

We also explored the role of the stress neurohormone corticotropin-releasing factor (CRF) in yohimbine-induced reinstatement of palatable food seeking by using a selective $\mathrm{CRF}_{1}$ receptor antagonist, antalarmin (Webster et al, 1996). Previous studies reported that systemic injections of a related $\mathrm{CRF}_{1}$ receptor antagonist $(\mathrm{CP}-154,526)$ attenuate footshock-stress-induced reinstatement of heroin, cocaine, and alcohol seeking (Shaham et al, 1998; Le et al, 2000). Finally, we used a social-interaction test (File, 1980) to independently verify the stress- and anxietylike effects of yohimbine and the impact of antalarmin on these effects.

\section{MATERIALS AND METHODS}

\section{Subjects and Apparatus}

Male Long-Evans rats (Charles River, Raleigh, NC; 300$380 \mathrm{~g}$ ) were housed in the self-administration chambers for the duration of the experiment under a reverse 12:12-h light-dark cycle (light off at 0930 hours). Rats were kept on a restricted diet of $20 \mathrm{~g} /$ day (about $75-80 \%$ of their regular daily Purina Rat Chow). The rats' body weight was taken daily $1-2 \mathrm{~h}$ prior to the start of the dark cycle (on two occasions, body weight was not measured due to snowstorms; for these days, body weights were estimated from those of the two preceding and subsequent days). The procedures followed the
'Principles of laboratory animal care' (NIH publication no. 85-23). Experiments were conducted in standard selfadministration chambers (Med Associates, Georgia, VT). Each chamber had two levers $9 \mathrm{~cm}$ above the floor, but only one lever ('active', retractable lever) activated the pellet dispenser, which delivered 45-mg food pellets containing $25 \%$ fat and $48 \%$ carbohydrate (Bioserv, Frenchtown, NJ).

\section{Drugs}

Yohimbine $\mathrm{HCl}$ (RBI) was dissolved in distilled water and was injected in a volume of $0.5 \mathrm{ml} / \mathrm{kg}$. The yohimbine dose used $(2 \mathrm{mg} / \mathrm{kg}$, i.p.) was based on previous work (Shepard et al, 2004; Le et al, 2005) and on a pilot experiment $(n=10)$ with a longer training period (22 sessions). During the reinstatement tests of this experiment, the number of active lever responses per $3 \mathrm{~h}$ were $20 \pm 2($ mean \pm SEM), $32 \pm 5,53 \pm 5$, and $64 \pm 11$, for vehicle and yohimbine doses of $0.5,1.0$ and $2.0 \mathrm{mg} / \mathrm{kg}$, respectively. Antalarmin was synthesized by one of the authors (KCR) and was dissolved just prior to drug injections in sterile saline containing $10 \%$ emulphor $\left(\mathrm{pH}=6.0\right.$; solutions were heated to $\left.70-80^{\circ} \mathrm{C}\right)$ and injected at a volume of $1 \mathrm{ml} / \mathrm{kg}$. The doses of antalarmin $(20$ and $40 \mathrm{mg} / \mathrm{kg}$, i.p.) are based on published reports (Briscoe et al, 2000; Zorrilla et al, 2002) and on previous studies using the $\mathrm{CRF}_{1}$ antagonist CP-154,526 (Shaham et al, 1998; Le et al, 2000).

\section{Procedures}

Experiment 1: reinstatement. The experiment included three phases: pellet self-administration training (24 days), extinction (10 days), and reinstatement tests (6 days).

Self-administration. Rats were given one 6-h daily session of 'autoshaping' during which pellets were administered noncontingently every $5 \mathrm{~min}$ into a receptacle located near the active lever. Pellet delivery was accompanied by a 5 -s tone-light cue. Subsequently, over a period of 24 days, the rats were trained every other day for $9 \mathrm{~h} /$ day (three 3 -h sessions separated by $1 \mathrm{~h}$ ) on a fixed ratio 1 (20-s timeout) schedule to self-administer the pellets. At the start of each session, the houselight was turned on and the active lever was extended. Following each pellet delivery, the tone-light cue was turned on for $5 \mathrm{~s}$. At the end of each session, the houselight was turned off and the active lever retracted. During the training days, regular food $(20 \mathrm{~g})$ was given immediately after the first 3-h daily session, which started at 1000 hours; during the off days, the $20 \mathrm{~g}$ regular food was given at the start of the dark cycle. Owing to experimenter error, on the 5th training day, the regular food was given after the end of the second 3-h training session; the data for the second and third 3-h sessions of that day were estimated from the corresponding values of the previous and subsequent training days.

Extinction. After training, the rats were given 10 daily extinction sessions. The experimental conditions were identical to those in training, except that responses did not lead to pellet delivery. Initially, the rats were given three 3-h sessions (separated by $1 \mathrm{~h}$ ) each day for 6 days. 
Subsequently, 3-h extinction sessions were given daily for 4 days, during which the rats were given daily injections of the yohimbine vehicle and the antalarmin vehicle in order to habituate them to the injection procedure. During the extinction phase, the regular food $(20 \mathrm{~g})$ was given immediately after the first 3-h daily session, which started at 1000 hours.

Tests for reinstatement. Initially, we tested the effect of antalarmin on yohimbine-induced reinstatement in two tests that were conducted 48-h apart under extinction conditions. On the intervening day, a regular extinction session was conducted. We used a factorial design, with the between-subjects factor of antalarmin dose $(0,20$, or $40 \mathrm{mg} / \mathrm{kg}$ ) and the within-subjects factor of yohimbine dose $(0$ and $2.0 \mathrm{mg} / \mathrm{kg})$. The rats were randomly assigned to the antalarmin dose groups. Yohimbine or its vehicle was injected $30 \mathrm{~min}$ before the test sessions, and antalarmin or its vehicle was injected $30 \mathrm{~min}$ before yohimbine. The order of yohimbine and its vehicle was counterbalanced. Subsequently, the rats were given an additional extinction session, and 1 day after that, we examined the effect of antalarmin on pellet-induced reinstatement. A pellet was delivered noncontingently at the beginning of this 3-h test session. This reinstatement test was also conducted under extinction conditions, and antalarmin or its vehicle was injected $30-60 \mathrm{~min}$ before the start of the session. During the testing phase, regular food $(20 \mathrm{~g})$ was given immediately after the 3-h daily sessions, which started at 1000 hours.

Experiment 2: social interaction. The social-interaction test is sensitive to the anxiogenic and anxiolytic effects of drugs (File and Seth, 2003). Exposure to stressors decreases social interaction in rats (Morilak et al, 2003), and this effect is reversed by $\mathrm{CRF}_{1}$ receptor antagonists (Gehlert et al, 2005). We used the social-interaction test to independently verify that under our experimental conditions, yohimbine induces stress- and anxiety-like responses that are reversed by antalarmin. A total of 16 rats previously used in Exp. 1 were placed in locomotoractivity chambers in eight weight-matched pairs. During the 10-min sessions, we scored the time spent in social interaction (grooming, sniffing, following, crawling o ver/under) and in 'antisocial'/aggressive interaction (wrestling, distress vocalization, confrontation), using measures derived from previous reports (see Morley and McGregor, 2000). The scorer was blind to the experimental conditions. In the first three baseline sessions, each rat was injected with the vehicles for antalarmin and yohimbine 60 and $30 \mathrm{~min}$, respectively, prior to being placed in the chambers. We used a nested factorial design with the within-subjects factors of antalarmin dose $(0$ and $20 \mathrm{mg} / \mathrm{kg}$ ) and yohimbine dose (0 and $2.0 \mathrm{mg} / \mathrm{kg}$ ) to evaluate the effect of antalarmin on the behavioral effects of yohimbine. Over four 10-min social-interaction sessions, one rat in each pair received antalarmin or its vehicle, as well as yohimbine or its vehicle. The other rat in each pair was not injected. Yohimbine was injected $30 \mathrm{~min}$ prior to these sessions, and antalarmin was injected $30 \mathrm{~min}$ prior to the injections of yohimbine. The order of the different combinations of the drug doses was counterbalanced.

\section{RESULTS}

Experiment 1: Yohimbine- and Pellet-Priming-Induced Reinstatement

Self-administration training and extinction. During the training phase, the rats (total $n=35$ ) were given 9-h access to the food pellets every other day. They gained weight when pellets were available and lost weight when they were not (Figure $1 \mathrm{~b}$ and $\mathrm{c}$ ). A nested repeated-measures ANOVA using pellet availability and training day as the factors and

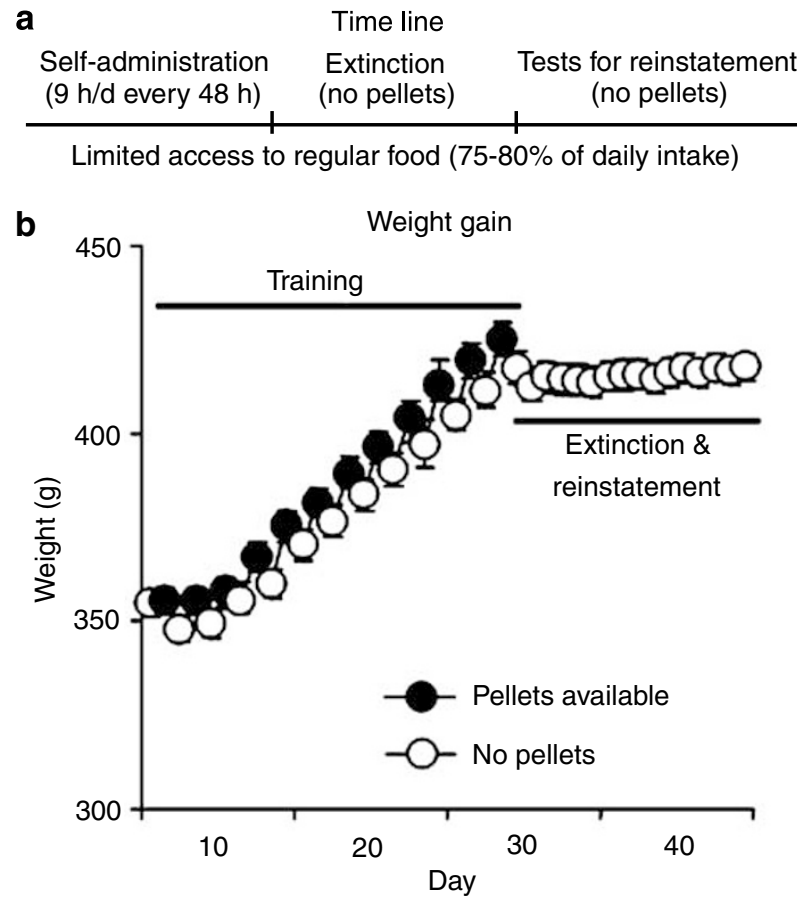

C

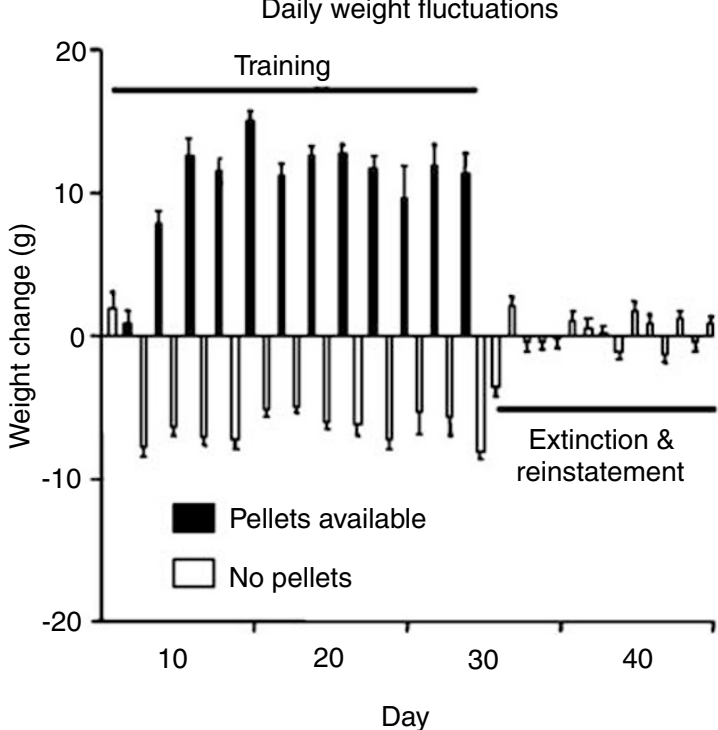

Figure I Weight gain and daily weight fluctuations. (a) Timeline of the experiment. (b) Mean \pm SEM weight (g) and (c) daily weight fluctuations during the experiment. During training, the palatable food pellets (25\% fat, $48 \%$ carbohydrate) were available for 9-h/day every other day; the food pellets were not available during the extinction and reinstatement phases $(n=35)$. 

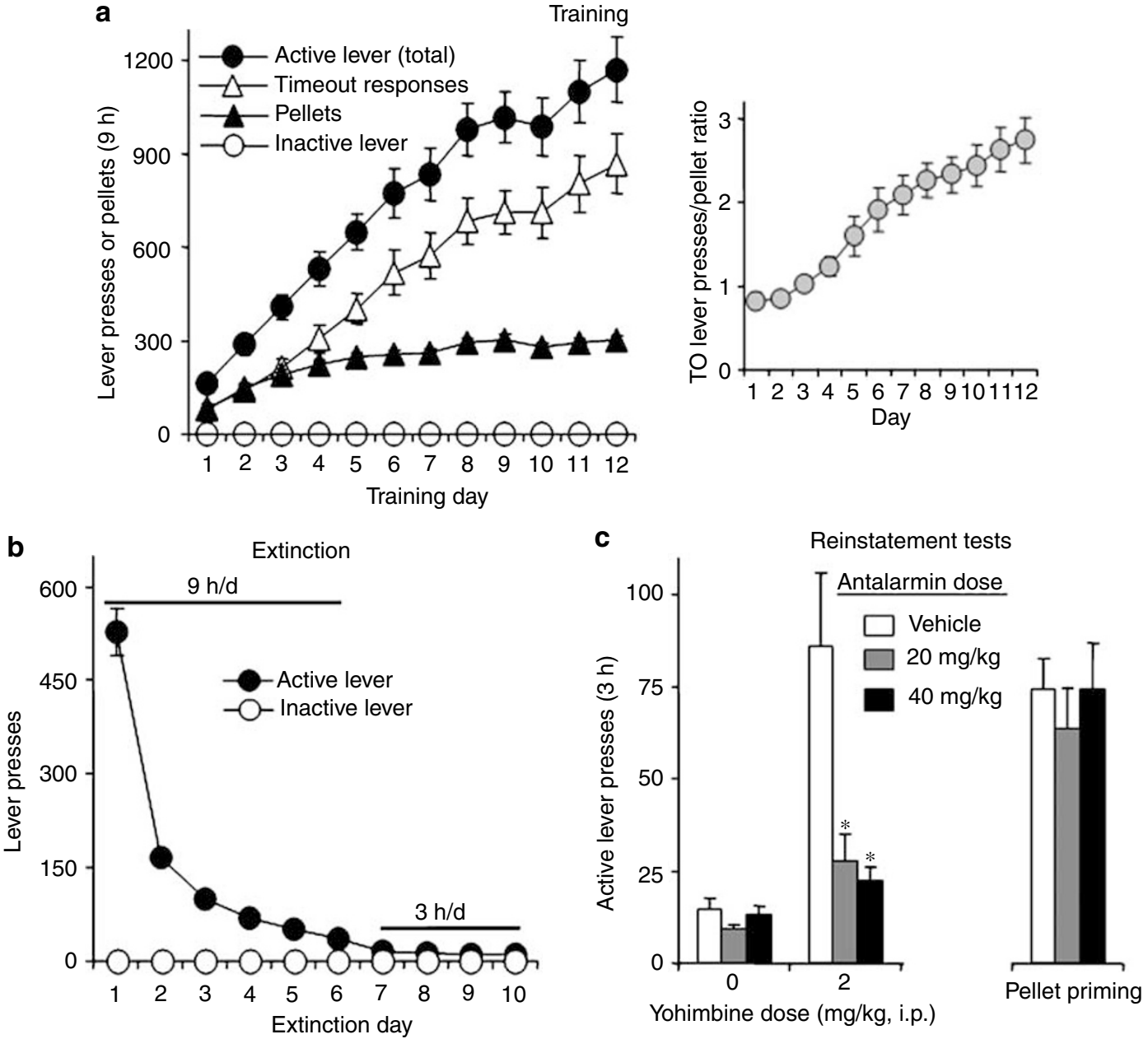

Figure 2 Training of palatable pellet self-administration, extinction, and reinstatement of food seeking. (a) Training: Mean \pm SEM number of pellets, total active lever presses (pellet earned + timeout responses), nonreinforced active lever presses during the 20-s timeout after pellet delivery, and inactive lever presses $(n=35)$. Right column: ratio of timeout nonreinforced lever presses to reinforced lever presses (ie pellets earned) during training (see text). (b) Extinction: Mean \pm SEM number of presses on the previously active lever and on the inactive lever during the extinction phase. The session duration was $9 \mathrm{~h}$ for sessions $1-6$, and $3 \mathrm{~h}$ for sessions $7-10$ ( $n=35)$. (c) Tests for reinstatement: Mean \pm SEM number of nonreinforced active lever presses during testing. Antalarmin or its vehicle was given $60 \mathrm{~min}$ before the test sessions and yohimbine or its vehicle was given 30 min before the test sessions. Antalarmin attenuated the reinstatement of lever responding induced by yohimbine, but not the pellet priming $(n=\mid 1-12$ per antalarmin dose condition). *Different from the antalarmin vehicle condition, $P<0.01$, post hoc Bonferroni test.

body weight as the dependent measure revealed a significant interaction between these factors $\left(\mathrm{F}_{11,374}=25.1\right.$, $P<0.01)$. This weight fluctuation was not observed during the extinction and reinstatement phases when the pellets were not available (Figure $1 \mathrm{~b}$ and $\mathrm{c}$ ). During training, the rats demonstrated reliable pellet self-administration (Figure 2a) with a 3.8-fold increase in pellets earned $\left(\mathrm{F}_{11,374}=67.0, P<0.01\right)$ and a 7.2 -fold increase in active lever presses for pellets $\left(\mathrm{F}_{11,374}=40.4, P<0.01\right)$; inactivelever presses were very low and did not change over time $(P>0.1$, Figure 2a). As training progressed, the number of nonreinforced lever presses during the 20-s timeout also substantially increased (10.3-fold) over time $\left(\mathrm{F}_{11,374}=34.5\right.$, $P<0.01)$. Thus, the ratio of timeout nonreinforced lever presses to reinforced lever presses (ie pellet earned) increased from 0.8 (day 1) to 2.7 (day 12) $\left(\mathrm{F}_{11,374}=28.3\right.$, $P<0.01$ ) in a roughly monotonic fashion (Figure $2 \mathrm{a}$ ). Lever pressing was extinguished over six 9 -h sessions (Figure $2 \mathrm{~b}$ ). A repeated-measures ANOVA revealed that active lever presses decreased significantly over those days $\left(\mathrm{F}_{5,170}=\right.$ 144.0, $P<0.01)$ and remained low over the subsequent four 3-h sessions $(P>0.1)$.

Reinstatement tests. Antalarmin attenuated reinstatement of lever responding induced by yohimbine, but not pellet priming (Figure 2c). For yohimbine, an ANOVA with antalarmin dose $(0,20,40 \mathrm{mg} / \mathrm{kg})$ as the between-subjects factor and yohimbine dose $(0,2 \mathrm{mg} / \mathrm{kg})$ as the withinsubjects factor revealed a significant interaction between these factors for active $\left(\mathrm{F}_{2,32}=9.4, P<0.01\right)$ but not inactive $(P>0.05)$ lever responses. For pellet priming, the analysis included the between-subjects factor of antalarmin dose and the within-subjects factor of pellet priming (priming, no priming); the data for the no-priming condition were derived from the session in which the three groups were pretreated with antalarmin or its vehicle and were injected with the yohimbine vehicle. This analysis revealed a main effect of pellet priming $\left(\mathrm{F}_{1,32}=99.7, P<0.01\right)$; the 
effect of antalarmin dose and the priming $\times$ dose interaction were not significant. Finally, responding on the inactive lever was very low (less than three presses per $3 \mathrm{~h}$ ) and was not altered by the experimental manipulations (data not shown).

\section{Experiment 2: Social Interaction}

Yohimbine decreased social behavior and profoundly increased 'antisocial'/aggressive behavior; these effects were reversed by the low dose of antalarmin (Figure 3). For social behavior, repeated-measures ANOVA with yohimbine dose and antalarmin dose as the within-subject factors revealed significant effects of yohimbine dose $\left(\mathrm{F}_{1,7}=18.0, P<0.01\right)$ and antalarmin dose $\left(\mathrm{F}_{1,7}=8.6, P<0.05\right)$. For 'antisocial'/
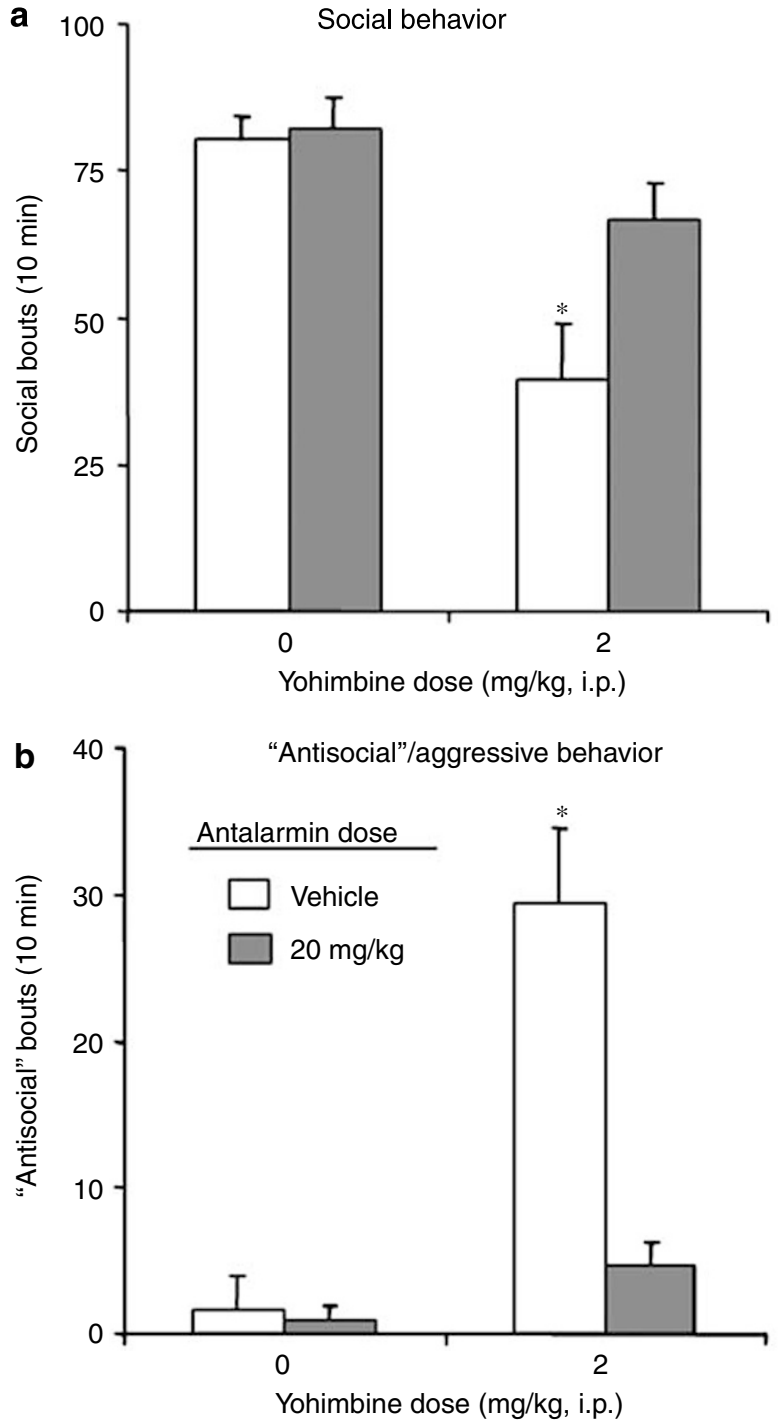

Figure 3 Effects of antalarmin and yohimbine on social interaction. (a) Social behavior: Mean \pm SEM occurrences of social behavior (grooming, sniffing, or crawling together) per $10 \mathrm{~min}$. (b) 'Antisocial'/aggressive behavior: Mean \pm SEM occurrences of aggressive/'antisocial' behavior (confrontation, distress vocalizations, or wrestling) per $10 \mathrm{~min}$. Yohimbine decreased social behavior (a) and increased 'antisocial'/aggressive behavior (b); these effects were reversed by antalarmin ( $n=8$ per condition). *Different from all other conditions, $P<0.01$, post hoc Bonferroni test. aggressive behavior, the analysis revealed significant effects of yohimbine dose $\left(\mathrm{F}_{1,7}=30.8, P<0.01\right)$ and antalarmin dose $\left(\mathrm{F}_{1,7}=19.1, P<0.01\right)$, and a significant interaction $\left(\mathrm{F}_{1,7}=21.6, P<0.01\right)$.

\section{DISCUSSION}

Stress and anxiety states can provoke relapse to maladaptive eating habits, and humans are particularly vulnerable to this effect when dieting (Herman and Polivy, 1975; Elfhag and Rossner, 2005). Surprisingly, this significant clinical phenomenon had not been studied in preclinical models. In the present report, we found that injections of yohimbine (which induces stress- and anxiety-like responses in humans and nonhumans) reinstate food seeking in food-restricted rats with a history of intermittent access to palatable food that led to escalation of lever responding for the food. The effect of yohimbine on reinstatement is similar in magnitude to that of acute priming exposure to the palatable food and is not likely due to the induction of hunger, as yohimbine does not increase food consumption in nonoperant procedures (Wellman, 2000). In our initial pharmacological characterization, we found that the $\mathrm{CRF}_{1}$ receptor antagonist antalarmin attenuates yohimbine-induced reinstatement of food seeking and also reverses the stress- and anxiety-like effects of yohimbine on social interaction in an ethologically valid model (File and Seth, 2003). Antalarmin had no effect on pellet-priming-induced reinstatement of food seeking, suggesting that its effect on yohimbine-induced reinstatement is not due to nonselective effects on lever responding or satiety. The selective effect of antalarmin on yohimbineinduced reinstatement of food seeking suggests that different neuronal mechanisms underlie relapse induced by stress $v s$ food stimuli.

\section{Role of Noradrenaline and CRF in Stress-Induced Reinstatement of Food Seeking}

We used yohimbine, which induces stress- and anxiety-like symptoms in humans and non-humans (Redmond and Huang, 1979), to examine the role of stress in reinstatement of palatable food seeking. Yohimbine increases central release of noradrenaline, which previous studies have shown to play a critical role in footshock stress-induced reinstatement of drug seeking (Erb et al, 2000; Shaham et al, 2000b; Leri et al, 2002). Thus, we interpret the present data to indicate that brain noradrenaline is involved in yohimbine-induced reinstatement of palatable food seeking. Yohimbine also binds to D2, $\alpha-1,5-\mathrm{HT} 1 \mathrm{a}$, and benzodiazepine receptors, but, as argued elsewhere (Shepard et al, 2004; Le et al, 2005), it is unlikely that the effect of yohimbine on reinstatement is mediated by these other receptors. In addition, Lee et al (2004) found that the effect of yohimbine on reinstatement of cocaine seeking is blocked by the $\alpha-2$ adrenoceptor agonist clonidine and mimicked by the selective $\alpha-2$ adrenoceptor antagonist RS-799948-197.

The main finding in this report is that the $\mathrm{CRF}_{1}$ receptor antagonist antalarmin attenuated the effect of yohimbine on reinstatement of palatable food seeking. In contrast, 
antalarmin had no effect on pellet-priming-induced reinstatement. This selective effect of antalarmin parallels results from previous studies with rats with a history of heroin or cocaine self-administration, in which ventricular injections of nonselective CRF receptor antagonists attenuated stress-induced but not drug-priming-induced reinstatement of drug seeking (Shaham et al, 1997; Erb et al, 1998). We do not yet know which brain sites mediate the effect of yohimbine on reinstatement of palatable food seeking or the blockade of this effect by antalarmin. One potential site is the bed nucleus of the stria terminalis (BNST). In this brain area, antagonism of either CRF receptors or $\beta$ adrenoceptors attenuates footshock-stressinduced reinstatement of cocaine seeking (Erb and Stewart, 1999; Erb et al, 2001; Leri et al, 2002). In addition, 6-OHDA lesions of the main input to the BNST, the ventral noradrenergic bundle originating from the lateral tegmental noradrenergic nuclei (Aston-Jones et al, 1999), attenuate footshock-stress-induced reinstatement of heroin seeking (Shaham et al, 2000b); see also Wang et al (2001) for a similar finding using a morphine conditioned place preference model. Another potential brain site is the ventral tegmental area (VTA). Wang et al (2005) recently reported that antagonism of VTA CRF receptors attenuates footshock-stress-induced reinstatement of cocaine seeking. Like the BNST, the VTA receives its main noradrenergic input from the lateral tegmental nuclei (Mejias-Aponte et al, 2004).

Alternatively, antalarmin may attenuate yohimbine-induced reinstatement of palatable food seeking by acting on CRF receptors in the paraventricular nucleus (PVN) of the hypothalamus to prevent release of the stress hormone corticosterone. Previous studies have shown that yohimbine modestly increases corticosterone release (Suemaru et al, 1989), presumably via activation of CRF neurons in the PVN (Plotsky, 1987). Other studies have shown that increased levels of corticosterone can promote palatable food intake in nonoperant procedures (Dallman et al, 2003). However, it is somewhat unlikely that yohimbine's hypothalamic effects are required for its effects on reinstatement of palatable food seeking. Previous studies have shown that footshock stress can reinstate heroin, cocaine, or alcohol seeking even when footshock-induced increase in corticosterone secretion is prevented by pharmacological or surgical (adrenalectomy) inhibition of corticosterone secretion (Shaham et al, 1997; Erb et al, 1998; Le et al, 2000). The data from these studies suggest that the effect of the CRF receptor antagonists on footshock-induced reinstatement of drug seeking is independent of their effect on the hypothalamic-pituitary-adrenal axis (Shaham et al, 2000a).

A potential caveat in generalizing from previous studies with cocaine, heroin, or alcohol-trained rats to the present work is that those studies used intermittent footshock, a stressor that does not reliably reinstate food seeking (Shaham et al, 2000a). Studies evaluating the effect of footshock on reinstatement of food seeking have been done either with nonpalatable food in deprived rats (Ahmed and Koob, 1997; Mantsch and Goeders, 1999) or with sucrose pellets or solutions in nondeprived rats (Le et al, 1998; Buczek et al, 1999). In both cases, rats were trained for 1-2 h/day, unlike our study where rats were trained $9 \mathrm{~h} /$ day every other day. Thus, methodological differences related to the type of food, limited $v s$ extended access, and food-deprivation levels might account for differences between these studies and our study. For example, the effect of yohimbine on reinstatement in food-sated rats is weaker and less reliable than in fooddeprived rats (unpublished data).

\section{Progressive Increase in Food-Taking Behavior during Training}

During the training phase, food-restricted rats given intermittent access to palatable food, which led to significant fluctuations in body weight (Figure 1), progressively increased their lever responding. It is unlikely that this increase is related to learning per se because early in training the rats clearly discriminated between the active and inactive levers (Figure 2). To our knowledge, this is the first demonstration of progressive escalation of food-taking behavior in an operant model. Our data extend results from nonoperant studies in which food-restricted rats given intermittent access to palatable food progressively increased their food intake, an effect interpreted to indicate the development of binge-eating habits (Colantuoni et al, 2001; Hagan et al, 2002, 2003; Corwin and Buda-Levin, 2004).

An interesting observation in the present study is that while pellet intake increased by less than four-fold over the first 5 days of training and then stabilized, the total number of nonreinforced lever presses during the 20-s timeout period after pellet delivery progressively increased by more than 10-fold over the 12-day training period (Figure 2a). This finding may parallel the results of Deroche-Gamonet et al (2004), who reported that cocaine-trained rats that developed an 'addictive-like phenotype' lever-pressed at much higher rates during timeout periods than rats that did not develop this phenotype. These authors argued that the persistence of nonreinforced operant responding, which developed following prolonged exposure to cocaine, reflects the development of compulsive drug-taking behavior, a defining characteristic of drug addiction. Thus, one interpretation of the progressive increases in timeout lever responding during training in our experiment is that the rats developed compulsive food-taking habits under conditions of restricted feeding and intermittent access to the palatable food.

It is also possible that the progressive increase in timeout lever responding was due to time-dependent increases in the incentive value of the cues associated with the intermittent access to the palatable food in hungry rats. During training, a discrete tone-light cue was present for $5 \mathrm{~s}$ during the timeout period after each pellet delivery. Such a cue can become a conditioned reinforcer that is likely able to maintain responding in the absence of the primary reinforcer (Catania, 1992). We are not familiar with studies that have systematically evaluated the motivational value of reward cues as a function of the duration of training. However, results from several recent studies indicate that reward seeking induced by cues progressively increases after withdrawal from heroin (Shalev et al, 2001; Di Ciano and Everitt, 2004), cocaine (Neisewander et al, 2000; Grimm et al, 2001; Lu et al, 2005), or sucrose (Grimm et al, 2002; Di Ciano and Everitt, 2004; Lu et al, 2004). Perhaps most 
relevant here, as we have found progressive within-subject increases in timeout lever responses, is the recent finding of Di Ciano and Everitt (2004). These authors used a withinsubject design and reported that over a period of 60 days, the conditioned reinforcing effects of cues paired with sucrose or heroin self-administration progressively increased when the rats were exposed to the cues intermittently. Interestingly, in that study, the rats were maintained on restricted feeding conditions similar to those employed in our study.

\section{Concluding Remarks}

We found that the pharmacological stressor yohimbine reinstates palatable food seeking in a preclinical model of relapse. These findings extend the recent observations of Hagan et al (2002, 2003), Dallman and co-workers (Pecoraro et al, 2004), and the earlier reports of Morley et al (1983) on the role of stress in palatable food-taking behavior. We also found that hungry rats that are given intermittent access to palatable food during training escalate their lever responding during nonreinforced timeout periods, suggesting the development of compulsive food-taking behavior and (or) increases in the motivational impact of the food-associated cues. The present findings and experimental procedures may have implications for the understanding of the neurobiological substrates of stress- or anxiety-associated relapse to maladaptive eating in humans. Major progress has been made over the last decade in the understanding of the neuronal and cellular substrates of ongoing feeding behavior in laboratory animals (Kelley and Berridge, 2002; Figlewicz, 2003; Horvath, 2005) and the role of stress in this behavior (Dallman et al, 2003). In contrast, the neuronal and cellular substrates of relapse to palatablefood seeking during periods of abstinence are unknown, despite the fact that relapse is the major clinical issue in the treatment of excessive and unhealthy eating. We hope that the relatively simple experimental procedure described here will facilitate research that advances the understanding of the mechanisms underlying relapse to maladaptive eating and leads to the development of treatment to prevent this relapse. In this regard, our data suggest that $\mathrm{CRF}_{1}$ receptor antagonists, currently in clinical development for the treatment of anxiety, depression, and drug addiction (Kehne and De Lombaert, 2002; Holsboer, 2003; Heidbreder and Hagan, 2005), should also be considered as pharmacological adjuncts in dietary treatments of maladaptive or excessive eating.

\section{ACKNOWLEDGEMENTS}

This research was supported (in part) by the Intramural Research Program of the NIH, the National Institute on Drug Abuse. We thank Dr Diane Lattemann for helpful comments on the manuscript.

\section{REFERENCES}

Abercrombie ED, Keller Jr RW, Zigmond MJ (1988). Characterization of hippocampal norepinephrine release as measured by microdialysis perfusion: pharmacological and behavioral studies. Neuroscience 27: 897-904.
Aghajanian GK, VanderMaelen CP (1982). Alpha 2-adrenoceptormediated hyperpolarization of locus coeruleus neurons: intracellular studies in vivo. Science 215: 1394-1396.

Ahmed SH, Koob GF (1997). Cocaine- but not food-seeking behavior is reinstated by stress after extinction. Psychopharmacology 132: 289-295.

Aston-Jones G, Delfs JM, Druhan J, Zhu Y (1999). The bed nucleus of the stria terminalis: a target site for noradrenergic actions in opiate withdrawal. Ann NY Acad Sci 877: 486-498.

Bossert JM, Ghitza UE, Lu L, Epstein DH, Shaham Y (2005). Neurobiology of relapse to heroin and cocaine seeking: an update and clinical implications. Eur J Pharmacol (in press).

Bremner JD, Krystal JH, Southwick SM, Charney DS (1996a). Noradrenergic mechanisms in stress and anxiety: I. Preclinical studies. Synapse 23: 28-38.

Bremner JD, Krystal JH, Southwick SM, Charney DS (1996b). Noradrenergic mechanisms in stress and anxiety: II. Clinical studies. Synapse 23: 39-51.

Briscoe RJ, Cabrera CL, Baird TJ, Rice KC, Woods JH (2000). Antalarmin blockade of corticotropin releasing hormone-induced hypertension in rats. Brain Res 881: 204-247.

Buczek Y, Le AD, Wang A, Stewart J, Shaham Y (1999). Stress reinstates nicotine seeking but not sucrose solution seeking in rats. Psychopharmacology 144: 183-188.

Catania CA (1992). Learning. Prentice-Hall: Englewood Cliffs.

Charney DS, Heninger GR, Redmond Jr DE (1983). Yohimbine induced anxiety and increased noradrenergic function in humans: effects of diazepam and clonidine. Life Sci 33: 19-29.

Colantuoni C, Rada P, McCarthy J, Patten C, Avena NM, Chadeayne A, Hoebel BG (2002). Evidence that intermittent, excessive sugar intake causes endogenous opioid dependence. Obes Res 10: 478-488.

Colantuoni C, Schwenker J, McCarthy J, Rada P, Ladenheim B, Cadet JL et al (2001). Excessive sugar intake alters binding to dopamine and mu-opioid receptors in the brain. NeuroReport 12: 3549-3552.

Corwin RL, Buda-Levin A (2004). Behavioral models of binge-type eating. Physiol Behav 82: 123-130.

Crowther JH, Sanftner J, Bonifazi DZ, Shepherd KL (2001). The role of daily hassles in binge eating. Int J Eat Disord 29: 449-454.

Dallman MF, Pecoraro N, Akana SF, La Fleur SE, Gomez F, Houshyar $\mathrm{H}$ et al (2003). Chronic stress and obesity: a new view of 'comfort food'. Proc Natl Acad Sci USA 100: 11696-11701.

Davis M, Redmond Jr DE, Baraban JM (1979). Noradrenergic agonists and antagonists: effects on conditioned fear as measured by the potentiated startle paradigm. Psychopharmacology (Berl) 65: 111-118.

de Wit H (1996). Priming effects with drugs and other reinforcers. Exp Clin Psychopharmacol 4: 5-10.

Deroche-Gamonet V, Belin D, Piazza PV (2004). Evidence for addiction-like behavior in the rat. Science 305: 1014-1017.

de Wit H, Stewart J (1981). Reinstatement of cocaine-reinforced responding in the rat. Psychopharmacology 75: 134-143.

Di Ciano P, Everitt BJ (2004). Conditioned reinforcing properties of stimuli paired with self-administered cocaine, heroin or sucrose: implications for the persistence of addictive behaviour. Neuropharmacology 47(Suppl 1): 202-213.

Elfhag K, Rossner S (2005). Who succeeds in maintaining weight loss? A conceptual review of factors associated with weight loss maintenance and weight regain. Obes Rev 6: 67-85.

Erb S, Hitchcott PK, Rajabi H, Mueller D, Shaham Y, Stewart J (2000). Alpha-2 adrenergic agonists block stress-induced reinstatement of cocaine seeking. Neuropsychopharmacology 23: $138-150$.

Erb S, Shaham Y, Stewart J (1998). The role of corticotropinreleasing factor and corticosterone in stress- and cocaineinduced relapse to cocaine seeking in rats. $J$ Neurosci 18: 5529-5536. 
Erb S, Shaham Y, Stewart J (2001). Stress-induced relapse to drug seeking in the rat: role of the bed nucleus of the stria terminalis and amygdala. Stress 4: 289-303.

Erb S, Stewart J (1999). A role for the bed nucleus of the stria terminalis, but not the amygdala, in the effects of corticotropinreleasing factor on stress-induced reinstatement of cocaine seeking. J Neurosci 19: RC35.

Figlewicz DP (2003). Adiposity signals and food reward: expanding the CNS roles of insulin and leptin. Am J Physiol Regul Integr Comp Physiol 284: R882-R892.

File SE (1980). The use of social interaction as a method for detecting anxiolytic activity of chlordiazepoxide-like drugs. J Neurosci Meth 2: 219-238.

File SE, Seth P (2003). A review of 25 years of the social interaction test. Eur J Pharmacol 463: 35-53.

Gehlert DR, Shekhar A, Morin SM, Hipskind PA, Zink C, Gackenheimer SL et al (2005). Stress and central urocortin increase anxiety-like behavior in the social interaction test via the CRF1 receptor. Eur J Pharmacol 509: 145-153.

Grimm JW, Hope BT, Wise RA, Shaham Y (2001). Incubation of cocaine craving after withdrawal. Nature 412: 141-142.

Grimm JW, Shaham Y, Hope BT (2002). Effect of the cocaine and sucrose withdrawal period on extinction behavior, cue-induced reinstatement and protein levels of the dopamine transporter and tyrosine hydroxylase in limbic and cortical areas in rats. Behav Pharmacol 13: 379-388.

Hagan MM, Chandler PC, Wauford PK, Rybak RJ, Oswald KD (2003). The role of palatable food and hunger as trigger factors in an animal model of stress induced binge eating. Int $J$ Eat Disord 34: 183-197.

Hagan MM, Wauford PK, Chandler PC, Jarrett LA, Rybak RJ, Blackburn K (2002). A new animal model of binge eating: key synergistic role of past caloric restriction and stress. Physiol Behav 77: 45-54.

Heidbreder CA, Hagan JJ (2005). Novel pharmacotherapeutic approaches for the treatment of drug addiction and craving. Curr Opin Pharmacol 5: 107-118.

Herman CP, Polivy J (1975). Anxiety, restraint, and eating behavior. J Abnorm Psychol 84: 66-72.

Holmberg G, Gershon S (1961). Autonomic and psychic effects of yohimbine hydrochloride. Psychopharmacologia 2: 93-106.

Holsboer F (2003). Corticotropin-releasing hormone modulators and depression. Curr Opin Investig Drugs 4: 46-50.

Horvath TL (2005). The hardship of obesity: a soft-wired hypothalamus. Nat Neurosci 8: 561-565.

Kehne J, De Lombaert S (2002). Non-peptidic CRF1 receptor antagonists for the treatment of anxiety, depression and stress disorders. Curr Drug Targets CNS Neurol Disord 1: 467-493.

Kelley AE, Berridge KC (2002). The neuroscience of natural rewards: relevance to addictive drugs. J Neurosci 22: 3306-3311.

Lang WJ, Gershon S (1963). Effects of psychoactive drugs on yohimbine induced responses in conscious dogs. A proposed screening procedure for anti-anxiety agents. Arch Int Pharmacodyn Ther 142: 457-472.

Le A, Shaham Y (2002). Neurobiology of relapse to alcohol in rats. Pharmacol Ther 94: 137-156.

Le AD, Harding S, Juzytsch W, Funk D, Shaham Y (2005). Role of alpha-2 adrenoceptors in stress-induced reinstatement of alcohol seeking and alcohol self-administration in rats. Psychopharmacology 179: 366-373.

Le AD, Harding S, Watchus W, Juzytsch W, Shalev U, Shaham Y (2000). The role of corticotropin-releasing factor in stressinduced relapse to alcohol-seeking behavior in rats. Psychopharmacology 150: 317-324.

Le AD, Quan B, Juzystch W, Fletcher PJ, Joharchi N, Shaham Y (1998). Reinstatement of alcohol-seeking by priming injections of alcohol and exposure to stress in rats. Psychopharmacology 135: $169-174$.
Lee B, Tiefenbacher S, Platt DM, Spealman RD (2004). Pharmacological blockade of alpha(2)-arenoceptors induces reinstatement of cocaine-seeking behavior in squirrel monkeys. Neuropsychopharmacology 29: 686-693.

Leri F, Flores J, Rodaros D, Stewart J (2002). Blockade of stressinduced, but not cocaine-induced reinstatement, by infusion of noradrenergic antagonists into the bed nucleus of the stria terminalis or the central nucleus of the amygdala. J Neurosci 22: 5713-5718.

Lu L, Grimm JW, Hope BT, Shaham Y (2004). Incubation of cocaine craving after withdrawal: a review of preclinical data. Neuropharmacology 47(Suppl 1): 214-226.

Lu L, Hope BT, Dempsey J, Liu SY, Bossert JM, Shaham Y (2005). Central amygdala ERK signaling pathway is critical to incubation of cocaine craving. Nat Neurosci 8: 212-219.

Lu L, Shepard JD, Scott Hall F, Shaham Y (2003). Effect of environmental stressors on opiate and psychostimulant reinforcement, reinstatement and discrimination in rats: a review. Neurosci Biobehav Rev 27: 457-491.

Mantsch JR, Goeders NE (1999). Ketoconazole blocks the stressinduced reinstatement of cocaine-seeking behavior in rats: relationship to the discriminative stimulus effects of cocaine. Psychopharmacology 142: 399-407.

Mejias-Aponte CA, Zhu Y, Aston-Jones G (2004). Noradrenegic innervatoin of midbrain dopamine neurons: prominent inputs from A1 and A2 cell groups. Soc Neurosci Abstr No. 465.4

Morilak DA, Cecchi M, Khoshbouei H (2003). Interactions of norepinephrine and galanin in the central amygdala and lateral bed nucleus of the stria terminalis modulate the behavioral response to acute stress. Life Sci 73: 715-726.

Morley JE, Levine AS, Rowland NE (1983). Minireview. Stress induced eating. Life Sci 32: 2169-2182.

Morley KC, McGregor IS (2000). ( \pm )-3,4-methylenedioxymethamphetamine (MDMA, 'Ecstasy') increases social interaction in rats. Eur J Pharmacol 408: 41-49.

Neisewander JL, Baker DA, Fuchs RA, Tran-Nguyen LT, Palmer A, Marshall JF (2000). Fos protein expression and cocaine-seeking behavior in rats after exposure to a cocaine self-administration environment. J Neurosci 20: 798-805.

Pecoraro N, Reyes F, Gomez F, Bhargava A, Dallman MF (2004). Chronic stress promotes palatable feeding, which reduces signs of stress: feedforward and feedback effects of chronic stress. Endocrinology 145: 3754-3762.

Peterson CB, Mitchell JE (1999). Psychosocial and pharmacological treatment of eating disorders: a review of research findings. J Clin Psychol 55: 685-697.

Plotsky PM (1987). Facilitation of immunoreactive corticotropinreleasing factor secretion into the hypophysial-portal circulation after activation of catecholaminergic pathways or central norepinephrine injection. Endocrinology 121: 924-930.

Redmond DEJ, Huang YH (1979). Locus coeruleus and anxiety. Life Sci 25: 2149-2162.

See RE (2002). Neural substrates of conditioned-cued relapse to drug-seeking behavior. Pharmacol Biochem Behav 71: 517-529.

Shaham Y, Erb S, Leung S, Buczek Y, Stewart J (1998). CP-154,526, a selective, non peptide antagonist of the corticotropin-releasing factor type 1 receptor attenuates stress-induced relapse to drug seeking in cocaine- and heroin-trained rats. Psychopharmacology 137: 184-190.

Shaham Y, Erb S, Stewart J (2000a). Stress-induced relapse to heroin and cocaine seeking in rats: a review. Brain Res Brain Res Rev 33: 13-33.

Shaham Y, Funk D, Erb S, Brown TJ, Walker CD, Stewart J (1997). Corticotropin-releasing factor, but not corticosterone, is involved in stress-induced relapse to heroin-seeking in rats. J Neurosci 17: 2605-2614. 
Shaham Y, Highfield D, Delfs JM, Leung S, Stewart J (2000b). Clonidine blocks stress-induced reinstatement of heroin seeking in rats: an effect independent of the locus coeruleus noradrenergic neurons. Eur J Neurosci 12: 292-302.

Shaham Y, Shalev U, Lu L, De Wit H, Stewart J (2003). The reinstatement model of drug relapse: history, methodology and major findings. Psychopharmacology 168: 3-20.

Shalev U, Grimm JW, Shaham Y (2002). Neurobiology of relapse to heroin and cocaine seeking: a review. Pharmacol Rev 54: 1-42.

Shalev U, Morales M, Hope B, Yap J, Shaham Y (2001). Timedependent changes in extinction behavior and stress-induced reinstatement of drug seeking following withdrawal from heroin in rats. Psychopharmacology 156: 98-107.

Shepard JD, Bossert JM, Liu SY, Shaham Y (2004). The anxiogenic drug yohimbine reinstates methamphetamine seeking in a rat model of drug relapse. Biol Psychiatry 55: 1082-1089.

Stewart J (2000). Pathways to relapse: the neurobiology of drugand stress-induced relapse to drug-taking. J Psychiatry Neurosci 25: $125-136$.

Stewart J, de Wit H (1987). Reinstatement of drug-taking behavior as a method of assessing incentive motivational properties of drugs. In: Bozarth MA (ed). Methods of Assessing the Reinforcing Properties of Abused Drugs. Springer-Verlag: New York. pp 211-227.

Suemaru S, Dallman MF, Darlington DN, Cascio CS, Shinsako J (1989). Role of alpha-adrenergic mechanism in effects of mor- phine on the hypothalamo-pituitary-adrenocortical and cardiovascular systems in the rat. Neuroendocrinology 49: 181-190.

Van Loon GR, Kvetnansky R, McCarty R, Axelrod J (1989). Stress: Neurochemical and Humoral Mechanisms. Gordon \& Breach Science Publishers S.A.: New York.

Volkow ND, Wise RA (2005). How can drug addiction help us understand obesity? Nat Neurosci 8: 555-560.

Wang B, Shaham Y, Zitzman D, Azari S, Wise RA, You ZB (2005). Cocaine experience establishes control of midbrain glutamate and dopamine by cortictotropin-releasing factor: a role in stressinduced relapse to drug seeking. J Neurosci 25: 5389-5396.

Wang X, Cen X, Lu L (2001). Noradrenaline in the bed nucleus of the stria terminalis is critical for stress-induced reactivation of morphine-conditioned place preference in rats. Eur J Pharmacol 432: $153-161$.

Webster EL, Lewis DB, Torpy DJ, Zachman EK, Rice KC, Chrousos GP (1996). In vivo and in vitro characterization of antalarmin, a nonpeptide corticotropin-releasing hormone (CRH) receptor antagonist: suppression of pituitary ACTH release and peripheral inflammation. Endocrinology 137: 5747-5750.

Wellman PJ (2000). Norepinephrine and the control of food intake. Nutrition 16: 837-842.

Zorrilla EP, Valdez GR, Nozulak J, Koob GF, Markou A (2002). Effects of antalarmin, a CRF type 1 receptor antagonist, on anxiety-like behavior and motor activation in the rat. Brain Res 952: 188-199. 